\title{
Joint Optimization of Dynamic Lot-sizing and Condition-based Maintenance
}

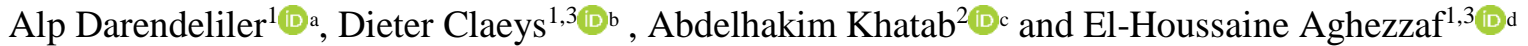 \\ ${ }^{I}$ Department of Industrial Engineering and Product Design, Ghent University, Gent, Belgium \\ ${ }^{2}$ Laboratory of Industrial Engineering, Production and Maintenance. Lorraine University. Metz, France \\ ${ }^{3}$ Industrial Systems Engineering (ISyE), Flanders Make, www.FlandersMake.be
}

Keywords: Condition-based maintenance, Lot-sizing, Stochastic dynamic programming.

\begin{abstract}
This study investigates the dynamic lot-sizing problem integrated with Condition-based maintenance (CBM) for a stochastically deteriorating production system. The main difference of this work and the previous literature on the joint optimization of lot-sizing and CBM is the relaxation of the constant demand assumption. In addition, the influence of the lot-size quantity on the evolution of the equipment degradation is considered. To optimally integrate production and maintenance, a stochastic dynamic programming model is developed that optimizes the total expected production and maintenance cost including production setup cost, inventory holding cost, lost sales cost, preventive maintenance cost and corrective maintenance cost. The algorithm is run on a set of instances and the results show that the joint optimization model provides considerable cost savings compared to the separate optimization of lot-sizing and CBM.
\end{abstract}

\section{INTRODUCTION}

Preventive maintenance operations aim to keep the equipment in operating condition and reduce the chance of having failures. Under Condition-based maintenance, they are performed based on the current condition of the equipment obtained through Condition monitoring (Jardine, 2005). It can significantly reduce maintenance cost by eliminating unnecessary scheduled preventive maintenance operations (Jardine, 2005).

To not interrupt the production, preventive maintenance actions should be conducted in accordance with the production plan in deteriorating production systems. Since machine deterioration depends on the amount of usage, the production planning decisions directly affect degradation of the systems. Thus, degradation of the equipment should be considered in determining production amounts. To address this issue, integrated optimization models of Economic Production Quantity (EPQ) and CBM were developed under the assumption of constant demand rate. Producing same quantity in each lot, leads to the same expected degradation path in those systems. Therefore, applying a static maintenance policy is convenient.

In a dynamic lot-sizing problem, however, production time and thus equipment usage within each period may differ, leading to different degradation paths. Using a static preventive maintenance threshold may not be optimal in this case. Therefore, for each period, a dynamic maintenance policy that considers future degradation paths with respect to different production quantities should be utilized.

This paper proposes a model to consider the current equipment condition and the evolution of the degradation with respect to production quantity in making production and maintenance decisions. Demanded quantities of the remaining periods, current condition of the equipment, and inventory level are the states that determine the production and maintenance policies for each period. The main difference of our work with the previous papers is the adaption of CBM to the multi-period lot-sizing problem under dynamic demand. In addition, in our

a https://orcid.org/0000-0000-0000-0000

b (D) https://orcid.org/0000-0000-0000-0000

c (D) https://orcid.org/0000-0000-0000-0000

d(D) https://orcid.org/0000-0000-0000-0000 
work, the influence of the quantity of the lot-size on the degradation level is taken into account in determining production decisions which has not been considered in this problem setting. We construct a stochastic dynamic programming model to minimize production setup cost, inventory holding cost, lost sales cost, preventive maintenance and corrective maintenance costs over finite and infinite horizons.

\section{LITERATURE REVIEW}

The joint optimization of lot-sizing and maintenance problem has been extensively studied under breakdown, time-based and age-based maintenance. Groenevelt et. al (1992) investigates the effect of machine breakdowns and corrective maintenance on the optimal production lot-sizes. They examine the effect of the failure rate on the optimal lot-size quantity. Ben-Daya and Makhdoum (1998) consider an integrated production and quality model for different inspection policies and they model the deterioration process using hazard rate function. They investigate the impact of different preventive maintenance policies on the EPQ. Ben-Daya (2002) proposes an integrated optimization model for lotsizing and imperfect preventive maintenance which adopts age-based maintenance policy. El-Ferik (2008) considers economic production lot-sizing for an unreliable machine under constant production and demand rates. Preventive maintenance actions are carried out when the age of the system reaches a predetermined level. After each preventive maintenance, the system becomes as good as new with a high failure rate. Thus, the system is replaced after a certain amount of production cycles are completed. Jafari and Makis (2015) study optimal lotsizing and preventive maintenance policy where the deterioration is modeled by a proportion hazards model which considers information gathered from condition monitoring and age of the system. They model and solve the problem as a semi-Markov decision process.

Stochastic dynamic programing models are also developed to optimize production and maintenance costs. Boukas and Liu (2001) propose a stochastic dynamic programming model to minimize maintenance and inventory holding costs by optimizing production and maintenance rates. Iravani and Duenyas (2002) consider an integrated maintenance and production control for a single item single machine production system with increasing failure rate. The demand is distributed as a stationary Poisson process. They formulate the problem as a
Markov Decision Process (MDP) where the states are degradation and inventory levels, and the actions are producing, idling and maintenance at each decision epoch. Sloan (2004) and Xiang et al. (2014) consider integrated production and maintenance planning subject to random production yield that changes with respect to the condition of the equipment. The maintenance and production planning decisions are made according to the degradation status of the equipment and yield. However, the influence of the production amount on the machine deterioration is not taken into account.

The joint optimization problem of Economic Production Quantity (EPQ) and CBM is studied under the assumption of constant production and demand rates. Peng and Van Houtum (2016) propose a joint optimization model of EPQ and CBM in which degradation is modeled as Gamma Process. Khatab et al. (2017) develop an integrated optimization model for production quality and CBM. The preventive maintenance threshold and inspection interval are the decision variables. However, the lotsize is not optimized. Cheng et. al (2017) propose a joint optimization model for production lot-sizing and CBM for a multi-component production system. Degradation of the components are modeled by Gamma process. They use Birnbaum importance measure to determine the preventive maintenance threshold of the components. Monte Carlo simulation technique is used to calculate the costs and genetic algorithm is utilized to find the optimal lot-size and preventive maintenance threshold.

Maintenance scheduling has been incorporated in the multi-item lot-sizing problems in which cyclic or non-cyclic maintenance actions are performed. Aghezzaf et. al (2007) propose an integrated production and preventive maintenance model for a capacitated multi-item production system in which the overall capacity of the system is reduced when a preventive or corrective maintenance is conducted. They consider capacity reduction of the production in case of failure or preventive maintenance. Preventive maintenance actions are carried out at periodic time points. Shamsaei and Van Vyve (2017) also develop an integrated model for multi-item lot-sizing and maintenance under time-varying demand. Additionally, they adapt non-cyclic maintenance schedules to their model which reduces the overall costs. However, preventive maintenance actions are performed without considering the health status of the component. 


\begin{tabular}{|c|c|}
\hline \multicolumn{2}{|l|}{ Nomenclature } \\
\hline$X(t)$ & $\begin{array}{l}\text { degradation level with respect to } \\
\text { time }\end{array}$ \\
\hline$X_{n}$ & $\begin{array}{l}\text { degradation level at the beginning of } \\
\text { period } n\end{array}$ \\
\hline$Z_{k}$ & $\begin{array}{l}\text { state of Markov chain right after the } \\
\text { production of } k^{t h} \text { unit within a } \\
\text { period }\end{array}$ \\
\hline$I_{n}$ & $\begin{array}{l}\text { inventory level at the end of period } \\
n\end{array}$ \\
\hline$T_{F}^{(i)}$ & $\begin{array}{l}\text { first passage time to failure from } \\
\text { state } i\end{array}$ \\
\hline$Q_{n}$ & production lot size in period $n$ \\
\hline$Q(i, y, n)$ & $\begin{array}{l}\text { optimal production lot size in period } \\
\mathrm{n} \text { for states } i \text { and } y\end{array}$ \\
\hline $\mathbf{1}_{n}\left(Q_{n}\right)$ & $\begin{array}{l}\text { indicator variable taking value } 1 \text { if } \\
\text { there is production in period } n\end{array}$ \\
\hline $\mathbf{1}_{n}\left(I_{n-1}+T_{F}^{(i)}\right.$ & $\begin{array}{l}\text { indicator variable taking value } 1 \text { if } \\
\text { there is enough inventory and }\end{array}$ \\
\hline$\left.-D_{n}\right)$ & $\begin{array}{l}\text { production to cover the demand up } \\
\text { to the failure }\end{array}$ \\
\hline$\rho$ & production rate per unit time \\
\hline$d_{n}$ & $\begin{array}{l}\text { constant demand rate per unit time } \\
\text { during period } n\end{array}$ \\
\hline$D_{n}$ & total demand in period $n$ \\
\hline$\tau$ & fixed time length of a period \\
\hline$N$ & finite number of periods \\
\hline$c_{h}$ & $\begin{array}{l}\text { inventory holding cost per unit of } \\
\text { time }\end{array}$ \\
\hline$c_{l}$ & lost sales cost per unit \\
\hline$c_{s}$ & production setup cost per lot \\
\hline$c_{p}$ & predictive maintenance cost \\
\hline & corrective maintenance cost \\
\hline$H N_{c}\left(Q_{n}, I_{n-1}\right)$ & $\begin{array}{l}\text { inventory holding as a function of } \\
Q_{n} \text { and } I_{n-1} \text { in case of no failure }\end{array}$ \\
\hline$H F_{c}\left(T_{F}^{(i)}, I_{n-1}\right)$ & $\begin{array}{l}\text { inventory holding as a function of } \\
T_{F}^{i} \text { and } I_{n-1} \text { in case of failure }\end{array}$ \\
\hline$L_{c}\left(T_{F}^{(i)}, I_{n-1}\right)$ & $\begin{array}{l}\text { lost sales cost as a function of } T_{F}^{i} \\
\text { and } I_{n-1}\end{array}$ \\
\hline$V_{n}\left(X_{n}, I_{n-1}\right)$ & $\begin{array}{l}\text { total minimum expected cost from } \\
\text { time } n \text { to the end of the planning } \\
\text { horizon }\end{array}$ \\
\hline$\gamma$ & discount factor \\
\hline
\end{tabular}

\section{SYSTEM DESCRIPTION}

We consider a production system in which the degradation of the machine is monitored continuously. Its level $X(t)$ increases with respect to the length of the production run-time. When the machine fails during the period, and thus the degradation having reached the "failure level" $F$, the production stops, and corrective maintenance is conducted. Note that in case of a failure during a period, the remaining units of production cannot be produced, although it was planned. To reduce the possibility of the failures, preventive maintenance actions are performed while the equipment is still in working condition.

At the beginning of each period $n$ with a fixed length $\tau$, a preventive maintenance decision is made and quantity of the production lot size $Q_{n}$ is determined according to the current degradation level $X_{n}$, the ending inventory of the previous period $I_{n-1}$, and known demand values of the remaining periods. The production rate $\rho$ is constant so the maximum amount of production in a period is limited to $\tau \rho$. If there is no failure within the production lot and thus the production plan is met for that period, there are two cases: (1) no maintenance is carried out so the starting degradation state of the next period is equal to the ending degradation state of the current period; (2) preventive maintenance is carried out at the beginning of the next period; in this case, starting degradation state of the next period becomes as good as new. Because maintenance duration is assumed to be negligible, carrying out maintenance at the end of the production time within a period or at the beginning of the next period does not make a difference for the model. To be comprehensible, it is assumed that maintenance actions are conducted at the beginning of the periods.

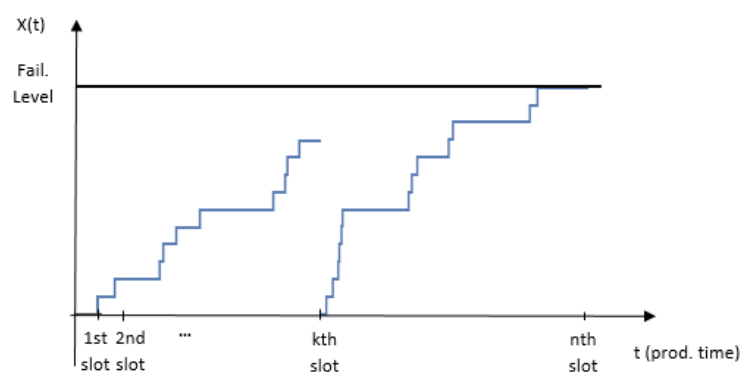

Figure 1. Sample degradation path with respect to production time.

Figure 1 shows an example of a sample degradation path starting from as good as new state with respect to the production time where preventive maintenance is carried out right after the completion of $k^{t h}$ item's production. The health status of the machine becomes as good as new after that point. A failure occurs after the production of the $n^{\text {th }}$ item so corrective maintenance is performed starting from this point. The corresponding graph of the inventory level with respect to the total time including the production and idle times are illustrated in Figure 2. During the idle times when the production capacity is 
not fully utilized, the degradation remains in the same level.

In the example shown, corrective maintenance is conducted in the $m^{\text {th }}$ period, starting right after the production of the $n^{\text {th }}$ item. Since there is not enough inventory to cover the demand at the $m^{\text {th }}$ period, lost sales occur. Figure 3 shows the case where sufficient amount of inventory is accumulated up to the failure, so no lost sales occurs. In the example shown in Figures 1 and Figure 2, up to the $m^{\text {th }}$ period, total amount of production is equal to $n\left(\sum_{k=1}^{m-1} Q_{k}<n<\right.$ $\left.\sum_{k=1}^{m} Q_{k}\right)$; which is less than the planned production amount due to the failure.

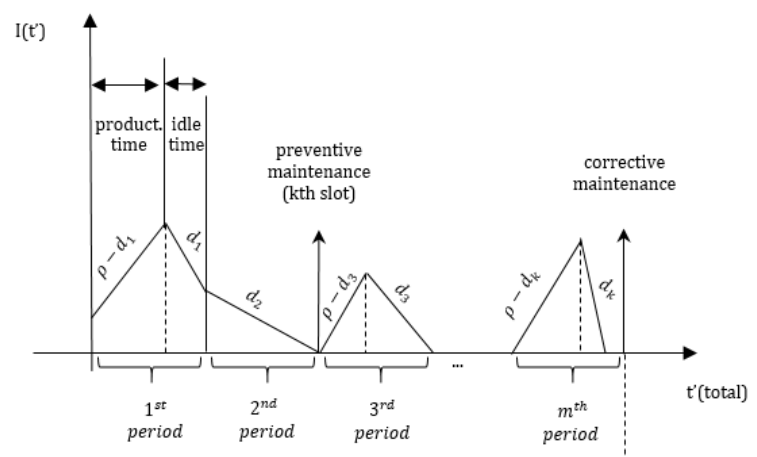

Figure 2. Inventory level with respect to total time including production and idle times.

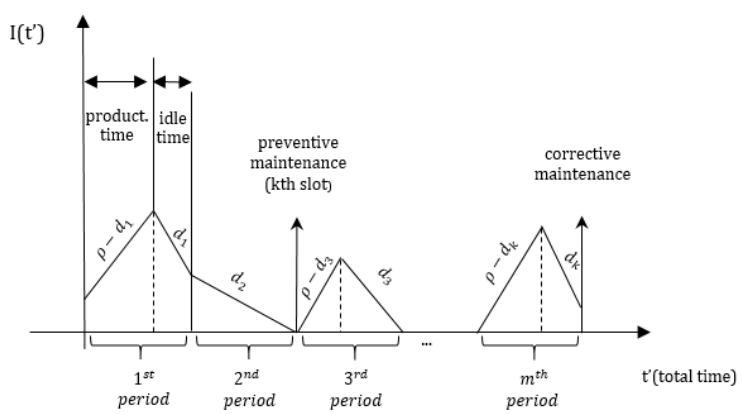

Figure 3. Inventory level with respect to total time including production and idle times.

\section{MODEL FORMULATION}

The evolution of the degradation during production time is modeled as a discrete-time stochastic process. The $k^{t h}$ epoch corresponds to the planned completion epoch of the $k^{t h}$ unit. As a result, the time in between two planned production epochs within the same period equals $1 / \rho$, with $\rho$ the production rate. The degradation level at epoch $k$ is denoted by $Z_{k}$. Within a period, the process $\left\{Z_{k}, k=0,1, \ldots\right\}$, behaves as an absorbing Markov chain with state space $\{0,1, \ldots, F\}$, absorbing state $F$, and transition probabilities $P_{i j}$ of degradation level transitioning to state $j$ at the next epoch if the degradation level is equal to $i$ at the current epoch. It is given by

$$
\begin{aligned}
& P_{i j}=P\left\{Z_{n+1}=j \mid Z_{n}=i\right\} \\
& \text { for } i \leq j \leq F
\end{aligned}
$$

As degradation cannot decrease during a period, $P_{i j}=0$ if $j<i$. $\boldsymbol{P}$ denotes the matrix of one-step transition probabilities $P_{i j}$. It can be expressed as

$$
P=\left[\begin{array}{ll}
T & t \\
0 & 1
\end{array}\right]
$$

where $\boldsymbol{T}$ is the probability transition matrix of the transient states of $\boldsymbol{P}$ (first $F$ row and columns of $\boldsymbol{P}$ ), and $\boldsymbol{t}$ is the column vector showing the probabilities from each state $i<F$ to the failure state $F$ (first $F$ rows of the last column of $\boldsymbol{P}$ ).

The $n$-step transition probability of the Markov chain from state $i$ to $j$ corresponds to the probability that the degradation is at level $j$ right after the production of the $n^{\text {th }}$ item within the same period. It is given by

$$
\begin{aligned}
& P_{i j}^{(n)}=P\left\{Z_{n}=j \mid Z_{0}=i\right\} \\
& \text { for } i \leq j \leq F
\end{aligned}
$$

Since $F$ is the absorbing state of the Markov chain,

$$
\begin{aligned}
& P_{F F}^{(k)}=P\left\{Z_{n+k}=F \mid Z_{n}=F\right\}=1 \\
& \forall k \in\{1,2, \ldots\} .
\end{aligned}
$$

$P_{i j}^{(n)}$ is equal to the entry at the $i^{\text {th }}$ row and $j^{\text {th }}$ column of the $n-$ step transition probability matrix $\boldsymbol{P}^{n}$.

If $Q_{n}$ items are planned to be produced in period $n$ and the degradation level at the beginning of the period is $i$, then $P_{i j}^{\left(Q_{n}\right)}$ is the probability that state $j<$ $F$ will be observed at the end of the production run. If a failure occurs right after the production of the $k^{t h}$ unit $\left(k<Q_{n}\right)$, before the production of the $Q_{n}{ }^{t h}$ unit, the production is stopped. The first passage time $T_{F}^{(i)}$, from state $i$ to the failure state $F$, has the phasetype distribution $P h\left(e_{i}, \boldsymbol{T}\right)$, that is

$$
P\left\{T_{F}^{(i)}=k\right\}=e_{i} \cdot \boldsymbol{T}^{\boldsymbol{k}-\mathbf{1}} \cdot \boldsymbol{t},
$$




$$
P\left\{T_{F}^{(i)} \leq k\right\}=1-e_{i} \cdot \boldsymbol{T}^{k} \cdot \mathbf{1}
$$

where $e_{i}$ is the $i^{\text {th }}$ unit vector. Note that $T_{F}^{(i)}$ takes values in terms of units of quantity produced up to the failure.

In case of no failure, the inventory holding cost in period $n$, where the production lot-size and initial inventory level are $Q_{n}$ and $I_{n-1}$, is given by

$$
\begin{aligned}
& H N_{c}\left(Q_{n}, I_{n-1}\right)= \\
& c_{h}\left[\frac{I_{n-1} Q_{n}}{\rho}+\frac{\left(Q_{n} / \rho\right)^{2}\left(\rho-d_{n}\right)}{2}\right. \\
& +\frac{\left(Q_{n}\left(\rho-d_{n}\right) / \rho-Q_{n}+D_{n}\right)\left(\tau-Q_{n} / \rho\right)}{2} \\
& \left.+\left(I_{n-1}+Q_{n}-D_{n}\right)\left(\tau-Q_{n} / \rho\right)\right],
\end{aligned}
$$

where $c_{h}$ is the inventory holding cost per item per unit time, $D_{n}$ is the total demand of the period $n$ and $d_{n}$ is the demand rate during period $n$ that is equal to $D_{n} / \tau$. The equation is obtained by the integration of the inventory level with respect to total time as illustrated in Figure 2; it is equal to the area under the curve within a period $n$.

At the beginning of a period, if the degradation is observed to be in state $i$, inventory level is $I_{n-1}$ and a failure occurs during production, then the inventory holding cost is expressed as

$$
\begin{aligned}
& H F_{c}\left(T_{F}^{(i)}, I_{n-1}\right)=c_{h} \\
& \left(1-\mathbf{1}_{n}\left(I_{n-1}+T_{F}^{(i)}-D_{n}\right)\right) \\
& \times\left[\frac{I_{n-1} T_{F}^{(i)}}{\rho}+\frac{\left(T_{F}^{(i)} / \rho\right)^{2}\left(\rho-d_{n}\right)}{2}\right. \\
& \left.+\frac{\left(I_{n-1}+T_{F}^{(i)}\left(\rho-d_{n}\right) / \rho\right)^{2} / d_{n}}{2}\right] \\
& +c_{h} \mathbf{1}_{n}\left(I_{n-1}+T_{F}^{(i)}-D_{n}\right) \\
& \times\left[\frac{\left(T_{F}^{(i)} / \rho\right)^{2}\left(\rho-d_{n}\right)}{2}\right. \\
& +\frac{\left(T_{F}^{(i)}\left(\rho-d_{n}\right) / \rho-T_{F}^{(i)}+D_{n}\right)}{2} \\
& \times\left(\tau-T_{F}^{(i)} / \rho\right)
\end{aligned}
$$

$$
\left.+\left(I_{n-1}+T_{F}^{(i)}-D_{n}\right)\left(\tau-T_{F}^{(i)} / \rho\right)\right]
$$

and the indicator variable is given by

$$
\begin{aligned}
& \mathbf{1}_{n}\left(I_{n-1}+T_{F}^{(i)}-D_{n}\right) \\
& =\left\{\begin{array}{ccc}
1 & \text { if } I_{n-1}+T_{F}^{(i)}-D_{n}>0 \\
0 & \text { otherwise. }
\end{array}\right.
\end{aligned}
$$

In case of a failure, two cases can occur: (1) the total demand is covered $\left(T_{F}^{(i)}+I_{n-1} \geq D_{n}\right)$; (2) demand is not met and lost sales cost is incurred $\left(T_{F}^{(i)}+I_{n-1}<D_{n}\right)$. The equations for calculating the area under the inventory level differs in these cases so indicator variable $\mathbf{1}_{n}\left(I_{n-1}+T_{F}^{(i)}-D_{n}\right)$ is used. In case of a failure, the lost sales cost is given by

$$
\begin{aligned}
& L_{c}\left(T_{F}^{(i)}, I_{n-1}\right) \\
& =c_{l} \max \left(0, D_{n}-I_{n-1}-T_{F}^{(i)}\right),
\end{aligned}
$$

where the initial degradation level is $i$ and the lost sales cost per item is $c_{l}$ as in the $m^{\text {th }}$ production lot (Figure 2). The dynamic programming equation in period $n$ for states $i<F$ and $I_{n-1}$ is expressed as

$$
\begin{aligned}
& V_{n}\left(X_{n}=i, I_{n-1}\right) \\
& =\underset{\max \left(D_{n}-I_{n-1}, 0\right) \leq Q_{n} \leq \min \left(C, \sum_{k=n}^{N} D_{k}\right)}{\min } \\
& {\left[\operatorname { m i n } \left[\sum _ { j = i } ^ { F - 1 } P _ { i j } ^ { ( Q _ { n } ) } \left(\mathbf{1}_{n}\left(Q_{n}\right) c_{s}+H N_{c}\left(Q_{n}, I_{n-1}\right)\right.\right.\right.} \\
& +\gamma V_{n+1}\left(j, I_{n-1}+Q_{n}-D_{n}\right) \\
& +\sum_{k=1}^{Q_{n}} P\left\{T_{F}^{(i)}=k\right\}\left(c_{s}+H F_{c}\left(k, I_{n-1}\right)\right. \\
& +L_{c}\left(k, I_{n-1}\right) \\
& \left.+\gamma V_{n+1}\left(F, \max \left(0, I_{n-1}+k-D_{n}\right)\right)\right) \\
& , c_{p}+\sum_{j=0}^{F-1} P_{0 j}^{\left(Q_{n}\right)}\left(\mathbf{1}_{n}\left(Q_{n}\right) c_{s}\right. \\
& +H N_{c}\left(Q_{n}, I_{n-1}\right) \\
& +\gamma V_{n+1}\left(j, I_{n-1}+Q_{n}-D_{n}\right) \\
& +\sum_{k=1}^{Q_{n}} P\left\{T_{F}^{(0)}=k\right\}\left(c_{s}+H F_{c}\left(k, I_{n-1}\right)\right. \\
& +L_{c}\left(k, I_{n-1}\right)
\end{aligned}
$$


$\left.\left.\left.+\gamma V_{n+1}\left(F, \max \left(0, I_{n-1}+k-D_{n}\right)\right)\right)\right]\right]$.

$C$ denotes the production capacity in terms of units, that is equal to $\rho \tau$. The feasible production lotsize $Q_{n}$ in state $\left(X_{n}, I_{n-1}\right)$, must be in $\left\{\max \left(D_{n}-\right.\right.$ $\left.\left.I_{n-1}, 0\right), \min \left(C, \sum_{k=n}^{N} D_{k}\right)\right\}$.

If a failure occurs in the previous period, then the initial degradation state at the beginning of the period $n$ is $F$, and the dynamic programming equation is given by,

$$
\begin{aligned}
& V_{n}\left(X_{n}=F, I_{n-1}\right) \\
& =\min _{\max \left(D_{n}-I_{n-1}, 0\right) \leq Q_{n} \leq \min \left(c, \sum_{k=n}^{N} D_{k}\right)}\left[c_{c}\right. \\
& +\sum_{j=0}^{F-1} P_{0 j}^{\left(Q_{n}\right)}\left(\mathbf{1}_{n}\left(Q_{n}\right) c_{s}\right. \\
& +H N_{c}\left(Q_{n}, I_{n-1}\right) \\
& \left.+\gamma V_{n+1}\left(j, I_{n-1}+Q_{n}-D_{n}\right)\right) \\
& +\sum_{k=1}^{Q_{n}} P\left\{T_{F}^{(0)}=k\right\}\left(c_{s}\right. \\
& +H F_{c}\left(k, I_{n-1}\right)+L_{c}\left(k, I_{n-1}\right) \\
& \left.\left.+\gamma V_{n+1}\left(F, \max \left(0, I_{n-1}+k-D_{n}\right)\right)\right)\right] .
\end{aligned}
$$

In this case, corrective maintenance is done and its cost $c_{c}$ is incurred. In the dynamic programming equations, the indicator variable $\mathbf{1}_{n}\left(Q_{n}\right)$ takes 1 if there is production in period $n$. It can be expressed as

$$
\mathbf{1}_{n}\left(Q_{n}\right)= \begin{cases}1 & \text { if } Q_{n}>0 \\ 0 & \text { otherwise }\end{cases}
$$

$V_{n}\left(X_{n}, I_{n-1}\right)$ is the total minimum expected cost between $n$ and $N$ and $0 \leq I_{n-1} \leq \min ((n-1) C-$ $\left.\sum_{i=1}^{n-1} D_{i}, \sum_{k=n}^{N} D_{k}\right)$. The ending value $V_{N}\left(X_{N}=\right.$ $\left.i, I_{N-1}\right)$, is 0 for all $X_{N}$ and $I_{N-1}$ and the final inventory level $I_{N}=0$. To find the optimal production and maintenance policy, enumeration is done over all feasible values of $Q_{n}$ in case of preventive maintenance and no preventive maintenance. Thus, the optimal policy for each period $n$, degradation level $i$ and initial inventory level $I_{n-1}$ is found. $V_{1}\left(X_{1}=0, I_{0}\right)$ is the total minimum expected cost value for the whole horizon where the initial degradation level $X_{1}$ is 0 and the initial inventory level is $I_{0}$. $C$ is the production capacity that is equal to the $\rho \tau$. The discount factor $\gamma$ is used for the infinite horizon case; it is taken as 1 for finite horizon problem.

\section{NUMERIC STUDY}

In this example, the degradation is modelled as a discrete-time Markov chain having 8 states. State 0 is the as good as new state and state 7 is the failure state. The mean time to failure from state 0 is 8.85 in terms of units produced. The inventory holding cost per item per unit time is $c_{h}=1$, the production setup cost is $c_{s}=150$, the cost of the preventive maintenance is $c_{p}=500$, the cost of the corrective maintenance is $c_{c}=1000$ and the cost of lost sales per item is $c_{l}=$ 500 . The problem is solved for changing demand values (Table 1) which are randomly generated integers in $\{0,10\}$ for finite horizon $N=10$. The production rate and fixed time length of one period are $\rho=2$ and $\tau=10$ respectively.

Table 1. Demand values for each period

\begin{tabular}{c|cccccccccc}
\hline Period & 1 & 2 & 3 & 4 & 5 & 6 & 7 & 8 & 9 & 10 \\
& & & & & & & & & & \\
Demand & 5 & 8 & 4 & 3 & 3 & 5 & 9 & 8 & 6 & 2 \\
\hline
\end{tabular}

Table 2. Optimal production and maintenance policies for each state and period.

\begin{tabular}{cccccc}
\hline \multicolumn{5}{c}{ Period(n) } \\
\cline { 2 - 6 } State & 6 & 7 & 8 & 9 & 10 \\
\hline$(0,2, \mathrm{n})$ & $13, \mathrm{~N}$ & $15, \mathrm{~N}$ & $12, \mathrm{~N}$ & $6, \mathrm{~N}$ & $0, \mathrm{~N}$ \\
$(1,2, \mathrm{n})$ & $12, \mathrm{~N}$ & $11, \mathrm{~N}$ & $12, \mathrm{~N}$ & $6, \mathrm{~N}$ & $0, \mathrm{~N}$ \\
$(2,2, \mathrm{n})$ & $8, \mathrm{~N}$ & $10, \mathrm{~N}$ & $7, \mathrm{~N}$ & $6, \mathrm{~N}$ & $0, \mathrm{~N}$ \\
$(3,2, \mathrm{n})$ & $6, \mathrm{~N}$ & $15, \mathrm{P}$ & $12, \mathrm{P}$ & $4, \mathrm{~N}$ & $0, \mathrm{~N}$ \\
$(0,3, \mathrm{n})$ & $13, \mathrm{~N}$ & $14, \mathrm{~N}$ & $13, \mathrm{~N}$ & $5, \mathrm{~N}$ & - \\
$(1,3, \mathrm{n})$ & $12, \mathrm{~N}$ & $11, \mathrm{~N}$ & $11, \mathrm{~N}$ & $5, \mathrm{~N}$ & - \\
$(2,3, \mathrm{n})$ & $11, \mathrm{~N}$ & $10, \mathrm{~N}$ & $11, \mathrm{~N}$ & $5, \mathrm{~N}$ & - \\
$(3,3, \mathrm{n})$ & $6, \mathrm{~N}$ & $14, \mathrm{P}$ & $5, \mathrm{~N}$ & $5, \mathrm{~N}$ & - \\
$(0,4, \mathrm{n})$ & $12, \mathrm{~N}$ & $13, \mathrm{~N}$ & $12, \mathrm{~N}$ & $4, \mathrm{~N}$ & - \\
$(1,4, \mathrm{n})$ & $11, \mathrm{~N}$ & $13, \mathrm{~N}$ & $10, \mathrm{~N}$ & $4, \mathrm{~N}$ & - \\
$(2,4, \mathrm{n})$ & $10, \mathrm{~N}$ & $9, \mathrm{~N}$ & $10, \mathrm{~N}$ & $4, \mathrm{~N}$ & - \\
$(3,4, \mathrm{n})$ & $5, \mathrm{~N}$ & $6, \mathrm{~N}$ & $4, \mathrm{~N}$ & $4, \mathrm{~N}$ & - \\
$(0,5, \mathrm{n})$ & $0, \mathrm{~N}$ & $12, \mathrm{~N}$ & $11, \mathrm{~N}$ & $3, \mathrm{~N}$ & - \\
$(1,5, \mathrm{n})$ & $0, \mathrm{~N}$ & $12, \mathrm{~N}$ & $9, \mathrm{~N}$ & $3, \mathrm{~N}$ & - \\
$(2,5, \mathrm{n})$ & $9, \mathrm{~N}$ & $8, \mathrm{~N}$ & $9, \mathrm{~N}$ & $3, \mathrm{~N}$ & - \\
$(3,5, \mathrm{n})$ & $5, \mathrm{~N}$ & $6, \mathrm{~N}$ & $4, \mathrm{~N}$ & $3, \mathrm{~N}$ & - \\
\hline
\end{tabular}

The optimal production and maintenance plan for the periods between 6 and 10 are shown in Table 2 for the specified degradation and inventory states. For the degradation state $i$ and the initial inventory level $y$ in period $n, Q(i, y, n)$ shows the optimal production quantity; optimal maintenance decision is 
shown by either performing preventive maintenance "P" or not "N". Since preventive maintenance is always carried out when degradation level is greater than or equal to 3 , same production quantities are optimal as in the degradation state 0 . Infeasible states are indicated by "_.". It can be seen from the Table 2 that if a preventive maintenance action is not carried out in a period, then optimal production quantity is non-decreasing with the degradation level for the same inventory level $y$. For instance, optimal production lot sizes for period $n=8$ and initial inventory level $y=5$ are: $Q(0,5,8)=1, Q(1,5,8)=$ 9, $Q(2,5,8)=9, Q(3,5,8)=4$.

\subsection{Sensitivity Analysis and Performance Evaluation}

In this part, the objective function values of the joint optimization model are compared with the separate optimization model. In the separate optimization model, first, the production plan is found by minimizing the production costs without considering maintenance. Then, optimal preventive maintenance decision for each state $\left(X_{n}, I_{n-1}\right)$ is found; the production quantities are known from the first stage.

The model is tested for different levels of the production setup cost $c_{s}$, the preventive maintenance $\operatorname{cost} c_{p}$ and the inventory holding $\cos t c_{h}$. The value of each parameter is changed while other parameters are kept at their initial values: $c_{s}=150, c_{h}=1, c_{l}=$ $500, c_{p}=250, c_{c}=1000, N=10$ and the total demand of each period is generated as a random integer in $[0,10]$ for each instance. The beginning and the ending inventory levels, $I_{0}$ and $I_{N}$ are both chosen as zero, and the initial degradation level $X_{1}$ is 0 .

The cost savings are calculated for five independently generated demand values, and they are shown in the following tables. Cost savings percentages are calculated by

$$
\frac{\left(C S_{1}\left(X_{1}, I_{0}\right)-V_{1}\left(X_{1}, I_{0}\right)\right) 100}{C S_{1}\left(X_{1}, I_{0}\right)}
$$

where $C S_{1}\left(X_{1}, I_{0}\right)$ is the total expected minimum cost of separate optimization model.

As shown in Table 3, the cost saving percentages of the joint optimization model are mostly at the highest level for the production setup cost $c_{s}=50$ and it decreases with the increasing values of $c_{S}$ for each instance. When the setup cost is high, the joint optimization model proposes higher production lot sizes which leads to higher risks of having failure.
Thus, the percentage of cost savings are low in this case. The optimal production lot-sizes are relatively low when the setup cost is lower, so the machine degrades less in each lot. Therefore, the possibility of having failures and lost sales are lower that leads to higher cost savings.

Table 3. Percentage of Saving (SP) for different values of setup cost $c_{S}$.

\begin{tabular}{llll}
\hline \multirow{2}{*}{ Instance } & 50 & 150 & 400 \\
\cline { 2 - 4 } 1 & $15.59 \%$ & $16.94 \%$ & $5.57 \%$ \\
2 & $14.45 \%$ & $10.88 \%$ & $5.94 \%$ \\
3 & $7.67 \%$ & $5.93 \%$ & $4.32 \%$ \\
4 & $19.04 \%$ & $12.8 \%$ & $6.05 \%$ \\
5 & $24.44 \%$ & $17.97 \%$ & $10.89 \%$ \\
Average & $16.24 \%$ & $12.90 \%$ & $6.53 \%$ \\
\hline
\end{tabular}

For higher levels of preventive maintenance cost values, the amount of the percentage of savings are observed to be less for each instance since changes in the production plans are less effective for reducing the overall costs (Table 4).

Table 4. Percentage of Saving (SP) for different values of preventive maintenance cost $c_{p}$.

\begin{tabular}{llll}
\hline \multirow{2}{*}{ Instance } & \multicolumn{3}{l}{$\mathrm{c}_{\mathrm{p}}$} \\
\cline { 2 - 4 } $\mathbf{2 5 0}$ & 500 & 750 \\
2 & $18.12 \%$ & $8.21 \%$ & $5.80 \%$ \\
3 & $16.72 \%$ & $5.66 \%$ & $3.25 \%$ \\
4 & $7.62 \%$ & $4.17 \%$ & $5.79 \%$ \\
5 & $13.96 \%$ & $5.34 \%$ & $2.99 \%$ \\
Average & $14.29 \%$ & $5.84 \%$ & $4.28 \%$ \\
\hline
\end{tabular}

Table 5 shows the cost savings of the separate and joint optimization models for three different levels of the inventory holding cost. When $c_{h}$ is low, optimal lot-sizes tend to be higher in the separate optimization model minimizing only production setup and inventory holding costs. Because keeping more inventory and having a smaller number of production runs minimize the total production costs, separate optimization model proposes higher quantities of production for low inventory holding cost values; therefore, there is a higher risk of having corrective maintenance and lost sales. 
Table 5. Percentage of Saving (SP) for different values of inventory holding $\operatorname{cost} c_{h}$.

\begin{tabular}{llll}
\hline \multirow{2}{*}{ Instance } & 0.5 & 1 & 2 \\
\hline 1 & $12.95 \%$ & $9.30 \%$ & $9.88 \%$ \\
2 & $15.47 \%$ & $7.39 \%$ & $5.52 \%$ \\
3 & $12.09 \%$ & $5.57 \%$ & $4.12 \%$ \\
4 & $15.73 \%$ & $14.63 \%$ & $9.36 \%$ \\
5 & $10.15 \%$ & $8.50 \%$ & $8.89 \%$ \\
Average & $13.28 \%$ & $9.08 \%$ & $7.55 \%$ \\
\hline
\end{tabular}

\section{CONCLUSIONS}

In this study, joint optimization of lot-sizing and CBM is studied under time-varying demand for a deteriorating production system. The effect of the lotsize on the machine degradation is considered. A stochastic dynamic programming model is constructed to find the optimal policy to minimize production setup cost, inventory holding cost, lost sales cost, preventive maintenance and corrective maintenance costs for finite horizon. The proposed optimal policy is dynamic; it gives the optimal production and maintenance decisions for each degradation state, inventory level and period so it minimizes overall costs from the current period to the end of the planning horizon.

Numeric study is conducted to present the optimal results of the model. Total costs of the joint and separate optimization models are calculated, and the cost savings are shown for the different levels of the cost parameters. The parameters in the numeric example are randomly selected to test the model. To test the applicability of the proposed model, it could be solved for the cases motivated by practice.

For future research, uncertain demand could be considered for the integrated optimization of lotsizing and CBM. Adapting the imperfect maintenance to our model, which relaxes the assumption that the machine is as good as new after each maintenance action, will be investigated. Multi-item production systems may be studied for the future research as well.

\section{REFERENCES}

Aghezzaf E.H., Jamali M., \& Ait-Kadi D. (2007). An integrated production and preventive maintenance planning model. European Journal of Operational Research, 181 (2), 679-685.

Ben-Daya M., Makhdoum M (1998). Integrated production and quality model under various preventive maintenance policies. Journal of the Operational Research Society, 49(8), 840-853.

Ben-Daya, M. (2002). The economic production lot-sizing problem with imperfect production processes and imperfect maintenance. International Journal of Production Economics, 76 (3), 257-264.

Boukas E., \& Liu Z. (2001). Production and maintenance control for manufacturing systems. IEEE Transactions on Automatic Control, 46 (9), 1455-1460.

Cheng Q. C., Zhou B. H., Li L. Joint optimization of lot sizing and condition-based maintenance for multicomponent production systems, Computers \& Industrial Engineering, 110, 538-549.

El Ferik S. (2008). Economic Production lot-sizing for an unreliable machine under imperfect age-based maintenance policy. European Journal of Operational Research 186(1):150-163.

Groenevelt H., Pintelon L., \& Seidmann A. (1992). Production lot sizing with ma chine breakdowns. Management Science, 38, 104-123.

Iravani S., \& Duenyas I. (2002). Integrated maintenance and production control of a deteriorating production system. IIE Transactions, 34 (5), 423-435.

Jardine, A., Lin, D., \& Banjevic, D. (2006). A review on machinery diagnostics and prognostics implementing condition-based maintenance. Mechanical Systems and Signal Processing, 20, 1483-1510.

Khatab A., Diallo C., Aghezzaf E. \& Venkatadri U. (2018). Integrated production quality and condition-based maintenance for a stochastically deteriorating manufacturing system. International Journal Production Research, 57(8). p.2480-2497.

Peng H., G.-J. Van Houtum. 2016. Joint Optimization of Condition-based Maintenance and Production Lotsizing. European Journal of Operational Research 253: 94-107.

Shamsaei F., Van Vyve M. (2017), Solving integrated production and condition-based maintenance planning problems by MIP modeling. Flexible Services and Manufacturing Journal, 29:184-202.

Sloan, T. W. 2004. "A Periodic Review Production and Maintenance Model with Random Demand, Deteriorating Equipment, and Binomial Yield." Journal of the Operational Research Society 55 (6): 647-656.

Xiang Y, Cassady CR, Jin T, Zhang CW (2014). Joint production and maintenance planning with machine deterioration and random yield. International Journal Production Research,52(6):1644-1657. 